\title{
Exploring Social Software at UBC Library: The TOTS Series
}

\author{
Lindsay Ure \\ Reference Librarian \\ David Lam Management Research Library \\ University of British Columbia \\ lindsay.ure@ubc.ca \\ Susan Atkey \\ Reference Librarian \\ Humanities \& Social Sciences \\ Walter C. Koerner Library \\ University of British Columbia \\ susan.atkey@ubc.ca \\ Katherine Miller \\ Reference Librarian \\ Woodward Library \\ University of British Columbia \\ katherine.miller@ubc.ca
}

\section{Keywords:}

Web 2.0, social software, collaboration, library 2.0, professional development

\section{Background}

The Tools for Outreach and Teaching Series (TOTS) was created in May 2007 to provide a venue for librarians and library staff at the University of British Columbia to explore emerging social software tools that might be used in their work in the library and for outreach and instruction. The creators and coordinators of the series are three reference librarians from different branches at UBC Library: Susan Atkey, Humanities and Social Sciences; Katherine Miller, Woodward Library (Life Sciences) and Lindsay Ure, David Lam Library (Business).

The series was born out of a desire to provide a collegial, informal, and non-threatening atmosphere for exploring emerging technologies and their potential use in an academic setting while reducing some of the fear of the unknown that often surrounds new technologies. The series acronym TOTS reflects the playful, exploratory approach to these potential new tools that the creators wanted to inform the sessions.

TOTS was inspired by other library efforts to address the need to keep pace with emerging technologies, such as the original PLCMC Learning 2.0 Program http://plcmcl2-about.blogspot.com/, the Five Weeks to a Social Library course http://www.sociallibraries.com/course/ , and Learning 2.0@Mac http://macetg.wordpress.com/2007/02/12/learning-20-mac-week-1/ 
The series is a grassroots effort which has enabled us to move quickly to keep pace (or, attempt to keep pace) with the seemingly never ending stream of new social software tools that are being developed.

Although the series is a grassroots enterprise, we did approach two relevant librarywide committees to sponsor the series, including assisting with facilitating group discussion and sponsoring refreshments for the sessions. We would like to acknowledge the support of the members of the eLibrary and the Reference and Instruction committees at UBC Library.

\section{Structure}

Each two hour session has three key elements: the speakers, the sandbox, and the discussion. Firstly, the series draws on local knowledge and experience. We have a standing invitation to all UBC librarians and library staff to speak about new tools they are passionate about using, either personally or professionally. We also approach librarians and staff who we know are already advocates or fans of a particular technology to participate as speakers, highlighting how they have applied these tools in their work.

The second core element is the focus on "hands on", exploratory learning, which is reflected in the series acronym TOTS. Each session provides participants with the opportunity to engage with the technology in an informal, experimental environment which we call "the sandbox". The format of the sandbox depends on the specific tool: it may involve bringing in laptops and letting staff try out specific tools, or setting up a wiki and inviting staff to create their own page.

Finally, each session includes a group discussion on the potential value of the tools to our work, and the advantages and challenges they might bring.

\section{Sessions}

Sessions are planned and offered at relatively quieter times of year, when we have fewer reference and instructional obligations and can think ahead and plan for the coming year.

Eight sessions have been offered so far:

Wikis

Virtual Worlds

Social Networking Tools

RSS

Social Bookmarking Tools

Google Tools: Part 1

Google Tools: Part 2

Real-Time Communication and Teaching Tools 
Another session, "Mobile Devices" is planned for July 2009. Most sessions have been attended by 30 or more participants, which is a full house for the teaching spaces we used. To date, 15 speakers, representing a number of UBC Library branches, have shared their experiences with their colleagues, some in multiple sessions. This series has involved the active participation of both library staff and librarians. A fundamental part of the philosophy of this series is to meet the needs of both of these groups.

\section{Coordinating TOTS}

The process of setting up a TOTS session starts with a brainstorming/planning session. We meet and discuss new social software and online tools we are using, have read about or that we are hearing about from our colleagues. From these brainstorming sessions, we identify potential speakers to approach and request their involvement. The process is both fast and fun as we are all actively engaged in exploring these new technologies.

In keeping with the exploratory, hands-on approach that is a core part of our mandate, we use social software tools themselves to support the series. For administrative and planning documents, the creators use Google Docs. This tool enables several people in different branches to work collaboratively on a document from anywhere with Internet access.

In addition, a TOTS wiki was set up. This wiki serves as: a resource for speakers and participants; a promotional tool for upcoming sessions; and an archive of materials for those unable to attend the sessions. As a collaborative tool it allows speakers to add links to resources, such as web sites and YouTube videos, that provide more information on their tool. The wiki was created using PBWiki (now known as PBWorks: http://pbworks.com/) and is freely available at http://tots.pbworks.com under a Creative Commons License.

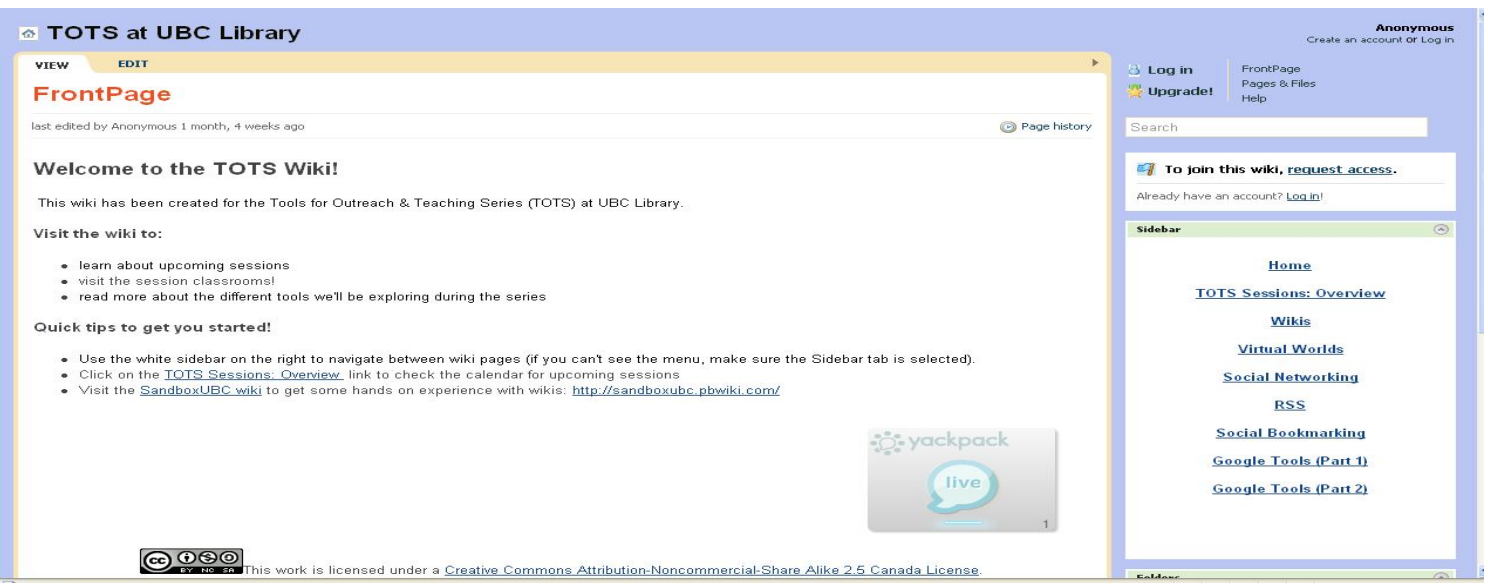


To receive feedback from staff and to ensure that the series remains relevant, an online survey is sent out to participants following each session. Survey Monkey, a freely available web-based survey tool is the tool of choice. Feedback is solicited on such elements as clarity and quantity of information, relevance of content to (one's) work, pace of session, and overall satisfaction, and is taken into consideration when developing subsequent sessions.

\section{Successes and Reflections}

In UBC Library's large, distributed system, TOTS replicates the small branch environment by providing an opportunity for information professionals who are "early adopters" or early explorers of new technologies to share some of the latest tools they are using with their colleagues. As with other professional development opportunities, TOTS efficiently helps librarians and library staff to proactively develop their skills as information leaders and helps us remain relevant to the needs of today's students and faculty.

The TOTS model has been very successful so far, with strong support and interest from library staff throughout the library system. In part this success comes out of the organic approach, with the creators evolving the series to keep up with new trends and remain relevant. As coordinators, we have learned that this creative approach is fun and rewarding and it encourages us to remain flexible in our approach to technology. With so many tools in perpetual beta and the likelihood that many will be short lived, the ability to remain agile and adapt to these changes is vital to our work.

\section{Tools}

Google Docs: http://docs.google.com/

PBWorks: http://pbworks.com/

Survey Monkey: http://www.surveymonkey.com/ 
Partnership: the Canadian Journal of Library and Information Practice and Research, vol. 4, no. 1 (2009)

\section{Works Cited}

Atkey, Susan, and Lindsay Ure. "Social Software: Keeping Up with our Students."

British Columbia Library Association Conference. Off the Shelf and Out of the

Box: Creativity in Libraries, Richmond, B.C., 17-19, April 2008

$<\underline{\text { http://eprints.rclis.org/13203/>>. }}$ 